\title{
13
}

\section{Business Model Innovation and the Development of the Electric Vehicle Industry in China}

Hua Wang and Chris Kimble

It is argued by many in the field of sustainable development that the need to use cleaner, more energy efficient and less environmentally damaging technologies has never been more urgent (Goldemberg, 1998), particularly in relation to transport and mobility (Romm, 2006). The problems of global warming and pollution, as well as issues of energy security, have acted as a spur to a global search for alternatives to the internal combustion engine (Jacobson, 2009).

Authors such as Zhao (2006) have argued that China's industrial policy is aimed at addressing these challenges and at positioning the country to take advantage of developments in alternative fuel vehicles in general and electric vehicles in particular. China's strategy of building a base of industrial competitiveness founded, in part, on 'new-energy vehicles' (a classification that includes pure electric, electric hybrid and other forms of alternative energy vehicles) means that China has now 
become a laboratory for the development of such vehicles, with several different types currently being evaluated by China's central and regional governments.

In previous articles (Wang and Kimble, 2010a and 2010b), we have focussed on China's capacity for technological innovation, however as Chesbrough observes, 'Technology by itself has no single objective value. The economic value of a technology remains latent until it is commercialized in some way via a business model' (Chesbrough, 2010: 354). Although it is not disputed that the development of new energy vehicles is a significant technological challenge, there are numerous examples to show that the successful adoption of technology involves more than producing a technologically elegant solution (Anand and William, 2008; Leavy, 2007). Consequently, in this chapter we turn to an examination of China's capacity for business model innovation rather than technological innovation.

\section{BUSINESS MODELS}

The term 'Business Model' is relatively new and has yet to establish a solid grounding in economic or management theory. Some trace use of the term to Chesbrough's analysis of technological innovation at Xerox (Chesbrough and Rosenbloom, 2002); others (Morris et al., 2005), trace it back to the mid 1990s, while, Magretta (2002) claims that the concept existed as long ago as the 1890s. Whatever the origin, most agree that the term first entered popular use during the so-called 'dot com bubble' at the turn of the century (Osterwalder et al., 2005). Although the term can be defined in a variety of ways (Amit and Zott, 2001; Magretta, 2002; Osterwalder et al., 2005; Teece, 2010), most agree that the organization of a firm's resources around the twin activities of value creation and value capture lie at the heart of a business model (Chesbrough, 2007). 
According to Teece (2010) a business model describes the way in which a firm 'delivers value to customers, entices it's customers to pay for value, and converts those payments to profit' (Teece, 2010: 172). A good business model means that a product offers value propositions that are compelling for customers, provide an advantageous infrastructure for the enterprise and generate a substantial revenue stream. An inappropriate business model means that a product will either fail to deliver value or fail to capture it. In this chapter, we do not enter into the debate about what constitutes a business model, but simply make use of the term to highlight the fact that, in order to extract value from a technology, some way to exploit it must to be found.

\section{Business model innovation}

Although a good business model is required for short-term commercial success, it does not guarantee long-term competitive advantage. As Teece notes, '... in practice, successful business models very often become, to some degree, 'shared' by multiple competitors' (Teece, 2010, 179). In order for a business model to continue to provide an advantage it must be clearly differentiated from others and difficult to imitate. The process by which such models are created has become known as business model innovation. The term was first popularized by Mitchell and Coles (2003 and 2004) and is built on earlier notions of 'disruptive technologies' (Bower and Christensen, 1995) and 'disruptive innovations' (Christensen, 1997).

A disruptive technology (Bower and Christensen, 1995) is a technology that disrupts an existing market by introducing a novel, and sometimes unlooked for, value proposition. At first, such technologies appear limited and only able to satisfy the needs of a particular niche market where the dimensions of performance at 
which they excel are valued. For the companies that serve mainstream markets, such technologies are perceived as irrelevant and, at least initially, ignored. However, over time, advances are made and the performance of the new technology improves until it reaches a point where it can satisfy the requirements of the mainstream market. At this point, the incumbent firms find they are unable to catch up with the conceptual and technological lead built up by those who focused on the disruptive technology and lose their position as market leaders.

Later Christensen broadened this idea to encompass innovation in general rather than specific technologies. He notes that:

'Generally, disruptive innovations were technologically straightforward, consisting of off-the-shelf components put together in a product architecture that was often simpler than prior approaches ... They offered a different package of attributes valued only in emerging markets remote from, and unimportant to, the mainstream'.

(Christensen, 1997: 15)

Mitchell and Coles (2003 and 2004) applied these ideas to business models and argued that similar advantages could be achieved by replacing an old business model with a new model that would leave competitors 'out of position and unable to respond effectively' (Mitchell and Coles, 2003: 15).

Markides (2006) however notes that although business model innovation and technological innovation are similar notions, they have one fundamental difference. Bower and Christensen's technological innovations first disrupt and then dominate a market. The effects of innovation in business models are less clear-cut; a new business model does not replace the existing business model completely but simply, 
‘... enlarges the existing economic pie ... business model innovators do not discover new products or services; they simply redefine what an existing product or service is and how it is provided to the customer.'

(Markides, 2006: 20)

Thus, the advantage gained by business model innovation is the way in which it allows the same basic product to be offered in a new way that yields more profit than a competitor could achieve using the current business model.

\section{Business model innovation and emerging markets}

London and Hart (2004) note that the approach to emerging markets taken by most multinational companies is one of 'Waiting for Westernization'.

'This perspective assumes that over time the local business environment will evolve into an economic setting that is familiar to Western managers: legal contracts will supersede social ones and competitive advantage will be grounded in the ability to protect resources and knowledge from unintended leakage outside firm boundaries.'

(London and Hart, 2004: 354)

They argue that by adopting this strategy companies miss out on the potentially huge returns from the poorer 'base of the pyramid' market. Christensen, Craig and Hart (2001) make a similar point. Commenting on General Motors' attempts to develop a competitively priced electric car, they note, 
'Globalization's real market opportunity lies with the billions of poor who are joining the market economy for the first time ... The crowded, polluted streets of Shanghai, Jakarta, and Bangkok could constitute a much more hospitable market for electric vehicles than do the expansive freeways of California.'

(Christensen, Craig and Hart, 2001: 92)

Most studies that look specifically at business model innovation in emerging markets focus on how firms from established economies adjust their business models to work in emerging markets. There appear to be very few studies that look directly at business models that have been developed within emerging markets. By ignoring developments in 'base of the pyramid' markets, we argue, companies also cut themselves off from a potential source of innovation and new ideas.

For example, Anderson and Markides' (2007) study of companies serving such markets in Africa, South Asia, East and Southeast Asia found innovation taking place at a number of levels. However, the companies they studied were those that had already been identified as having 'succeeded in serving customers living in poverty' (Anderson and Markides , 2007: 28). In practice, most were local subsidiaries of multinational companies that had overcome the problems of the affordability, acceptability, availability and awareness of their products in these markets.

Hart and Christensen (2002) is one of the first papers to draw attention explicitly to the value of business models that originate in emerging markets. Citing examples such as the Japanese firm Honda's success in selling low cost motorcycles to the US in the 1960's and the Chinese firm Calanz's success in selling low cost microwave cookers to Chinese consumers they note, 
'... business models that are forged in low-income markets travel well; that

is, they can be profitably applied in more places than models defined in high income markets'.

(Hart and Christensen, 2002: 52)

Sánchez and Ricart (2010) have conducted one of the few recent studies directed specifically at the business models used in 'base of the pyramid' markets. They analyzed the business models used by seven companies that operate in lowincome markets and evaluated their success. However, once again, most of the firms were companies that had originated elsewhere; only a few of the firms were based in the countries in which those markets exist.

\section{Summary}

To summarize, environmental and geopolitical pressures have provided the driving force behind the search for alternative sources of motive power. In technological terms, firms from Europe and North America are probably leading the race, but firms from emerging economies such as Brazil, Russia, India and China are actively pursuing the same goal. However, although mastery of the technology is important, it is not the sole criterion of success as, 'The economic value of a technology remains latent until it is commercialized in some way via a business model' (Chesbrough, 2010: 354). Although business models from emerging economies have not been the focus of many studies, we believe there are two reasons why an improved understanding of these models might be of value.

Firstly, the pressures that drive the search for alternative sources of motive power globally have been brought into particular focus by the growing pace of industrial development in the emerging economies. Thus, for a solution to be 
effective, it must be acceptable in, and applicable to, emerging as well as developed economies. As we have seen (Anderson and Markides, 2007; Sánchez and Ricart, 2010), a business model does not have to be developed in an emerging economy to be successful, however, as we have argued previously (Wang and Kimble, 2011), the likelihood of success will be greater if it is.

Secondly, the use of the gasoline powered automobile, at least in Europe and America, is well established and the problems of breaking our 'dependency' on the car has long been a topic of debate (Newman et al., 1995). There is anecdotal evidence from studies (Hart and Christensen, 2002) that business models developed in emerging economies have the potential to be disruptive in a similar fashion to Bower and Christensen's original notion of disruptive technologies (Bower and Christensen, 1995). It is possible that a novel business model, from an emerging economy or elsewhere, could be sufficiently disruptive to provide a solution to Europe and America's fascination with the internal combustion engine.

The next section briefly reviews the move towards new-energy vehicles in China and then looks at a case study of a company that produced a specific form of new-energy vehicle, the low speed electric vehicles (LSEV). The case study is of particular interest as it contains many of the features associated with disruptive technologies and business models.

\section{E-MOBILITY IN CHINA}

The electric vehicle industry, sometimes termed the e-mobility industry, began to develop in China in the early 1990s. In addition to electric cars, LSEV includes electric bikes, electric scooters and electric motorcycles. E-bikes are simple bicycles with an electric motor with an average speed of $20 \mathrm{~km} / \mathrm{h}$. E-scooters and 
e-motorcycles are equipped with heavier motors (1-5 kW) and have speeds of between $40-80 \mathrm{~km} / \mathrm{h}$. Production of two-wheeled e-vehicles grew to 25 million units in 2010 and production volumes are expected to reach 35 million in 2015. However, despite the high volume of production, the industry is still at an early stage of growth. Currently the sector consists of around 2700 licensed producers. The market share of the top 50 companies is only around 50 per cent, much lower than a mature industry.

With 140 million users of e-bicycles, e-scooters and e-motorcycles, e-mobility solutions are widely accepted by Chinese consumers as the answer to their basic transportation needs. Ninety percent of the total production of e-bikes is for the domestic market. The acceptance of low-speed electric transport forms the base for a potential market for the LSEVs that we will describe shortly. In addition to these consumers, there were 500 million users of standard bicycles in 2009. Over time, it is expected that a significant number of these will move to e-bicycles, e-scooters or e-motorcycles and that some, together with a proportion of the 140 million current e-mobility users, will switch directly to LSEVs. Based on the modest assumption of five per cent of bicycle and current e-mobility users switching to LSEVs, the market for LSEVs in China would amount to around 32 million people.

\section{Defining the low-speed electric vehicle}

There is currently no international consensus concerning the definition of a LSEV and even in China, one of the leading producers of LSEVs, the LSEV is not officially recognized as a road vehicle. Below we describe the key features of a LSEV in China together with a brief outline of how the LSEV is viewed in the United States and in Europe. 


\section{China}

The typical LSEV is composed of an accelerator, brakes, steering wheel and a lead acid battery pack. Gearshifts, air-conditioning and safety equipment are omitted to reduce the total costs. The electric motor is connected directly to the speed controller and most models do not have a sophisticated battery management or motor control system. A typical LSEV has a top speed of between 40 and $70 \mathrm{~km} / \mathrm{h}$, the dimensions of a compact car and weigh less than $1100 \mathrm{~kg}$. The lead acid battery can be recharged from a 220 volt home electric outlet and has a capacity of 120$250 \mathrm{Ah}$, giving a cruising distance of $80 \mathrm{~km}, 100 \mathrm{~km}$ or $150 \mathrm{~km}$, depending on the number of battery packs.

As a rule, LSEVs cannot be used on the road in China; there are two main reasons for this. Firstly, the companies that produce LSEVs are not listed in the 'Announcement of Vehicle Producers and Vehicle Products', published by the Ministry of Industry and Telecommunication; thus, any products they produce are not recognized as road vehicles. Secondly, the 'Law of Road and Transportation Security', which applies to the whole of China, does not have any policies or regulations to cover the use of LSEVs; consequently, in law, LSEVs have no right to use the road.

However, although modifications to these regulations are not normally permitted, as we shall see, provincial governments in areas where LSEVs are produced have created 'temporary' local policies that include permission to use LSEVs on the road as well as road tax and road charge waivers for the owners of LSEVs. 
$U S A$

In the USA, LSEVs are defined by Federal Motor Vehicle Security Standard N500 and Federal Crash Test Protocol TP-500-02. They are four-wheel electric vehicles that can be driven on the road, are fitted with certain basic safety features, have their speed limited to $56 \mathrm{~km} / \mathrm{h}$ and have an unladen weight less than $1362 \mathrm{~kg}$.

Most LSEVs have a product architecture based on golf carts, are powered by lead-acid batteries and have a top speed of between $32 \mathrm{~km} / \mathrm{h}$ and $40 \mathrm{~km} / \mathrm{h}$.

According to the National Highway Traffic Safety Administration, they are mostly used for short-distance transportation, shopping and recreation, by retired persons and by golfers.

Currently, 46 states, with the exception of Connecticut, Mississippi, Montana and Pennsylvania, have legalized the use of LSEVs on roads. The speed limit in Texas and Alaska has been extended to $72 \mathrm{~km} / \mathrm{h}$. The leading American company, GEM, an affiliate of Chrysler established in 1998, had sold more than 100,000 units (including three-wheelers) to 75 countries by the end of 2009 .

\section{Europe}

At present, there is no agreed standard for LSEVs; the nearest there is to a definition of a LSEV is that of a quadricycle. Quadricycles are small, four-wheeled, motorized vehicles, powered by either internal combustion engines or electric motors, which have certain restrictions on weight, power and speed. France was the 
first country to define Quadricycles in 1986; this was followed by European Union directive 92/61/EEC in 1992, and directive 2002/24/EEC in 2002.

Two categories of Quadricycle correspond to the notion of a LSEV: L6e and L7e Quadricycles. L6e (light) Quadricycles powered by electric motors with a power of less than $4 \mathrm{~kW}$, have a maximum unladen weight of $350 \mathrm{~kg}$ and a top speed of $45 \mathrm{~km} / \mathrm{h}$. The technical requirements of L6e are broadly in line with threewheel mopeds (category L2e).

L7e (heavy) Quadricycles have a maximum unladen weight of $400 \mathrm{~kg}(550 \mathrm{~kg}$ for models that carry goods), a maximum power of $15 \mathrm{~kW}$ and a top speed of 60 $\mathrm{km} / \mathrm{h}$. No crash testing is required for either L6e or L7e and many European countries class these as category B vehicles that do not require a driver's licence for their use.

\section{BUSINESS MODEL INNOVATION: THE SHIFENG GROUP}

Below we present a case study of the Shifeng Group, one of the largest producers of LSEVs in China. This case study is of particular interest as an illustration of the role of the business model and business model innovation. Firstly, in terms of business models, it is an example of a product that is still in the process of being defined: the technology for the product exists but an appropriate means of commercializing it does not. Secondly, in terms of business model innovation, it also illustrates a market for a product that corresponds closely to Christensen's notion of a disruptive technology and has grown, so far, without the support of central government and outside the boundaries of the mainstream automobile industry. 


\section{Background}

The Shifeng (Group) Co., Ltd. is state owned enterprise, which operates under the jurisdiction of the regional government of Shandong Province. It was established in 1993 and began the production of low-speed, three-wheeled, diesel powered, light trucks. Although low-speed three-wheeled trucks are its core business, amounting to a total production of 1.25 million vehicles, since 2008 , Shifeng has become one of the key players in developing the market for LSEVs. The group's sales revenue in 2010 was 23.6 billion $¥$ ( $\$ 3.6$ billion) and the cumulative sales of their lowspeed three and four-wheel vehicles has reached over seven million units. Shifeng is still lead by its founder, Mr. Liu Yifa, although his son, Liu Cheng Qiang, became the firm's General Manager in 1999. Further information on the history and background of this case study can be found elsewhere (Wang and Kimble, 2011).

\section{Methodology}

Broadly speaking, the methodology we employed is that of a descriptive case study (Yin, 2003). However, the methodology departs from the comparative or iterative approach described by Yin (2003) and Eisenhardt (1989) in that the analysis is, in part, a re-analysis of data collected in earlier case studies and, in part, the analysis of data that has been collected more recently. It also departs from the strict view of a descriptive case study, where the researcher sets out to explore cause-effect relationships using a set of propositions derived from existing theory, as some areas of existing theory, such as business models and business model innovation, were not sufficiently developed. Consequently, our approach to the case study is 
also exploratory, as the use of these concepts, particularly within emerging economies, is not well developed.

The first contact with the company dates back to PhD research in 2001 (Wang, 2002). In 2008, just after the first LSEVs had been produced, the president of the Shifeng group, Mr. Liu Yifa was interviewed. Members of industrial associations, competitors and journalists were interviewed during late 2010 and early 2011, to gain a broader view on the emerging market for LSEVs. These included the Director of the Technology Service Center for Electric Vehicles, the China Electric Engineering Technology Association, the President of Shanghai Kanleqiu Science and Technology Company and a Project General Manager of Sina-Newchance New Energy Technology Co. Ltd.

\section{Building a business model for LSEVs}

Currently, the main market for LSEVs in China is in rural areas. More than 70 per cent of the population of China, around 900 million people, live in such areas; however, their purchasing power is much lower than those who live in the cities. Consequently, the business model for LSEVs that has evolved has, so far, been aimed at servicing the needs of these consumers.

According to the China Statistical Yearbook (2010), the per capita annual income of rural households was $5153 ¥$ (\$790), compared to $17,175 ¥(\$ 2650)$ for urban households, giving rural consumers an income of less than a third of those who live in urban areas. Khan and Riskin (1998) found an increasing disparity between urban and rural areas between 1988 and 1995 while Yang and Hao (1999) show that this disparity has been growing since the opening up of the Chinese economy in the 1980s. Ranis, (1988: 74) describes this as a dual economy where 
'two sectors which are basically asymmetrical - and thus dualistic - in terms of both product and organisational characteristics' co-exist.

The dual-structure of the Chinese economy is key factor in the development of the business model for LSEVs. At 25,000 $(\$ 3900$ ), the purchase price of a LSEV is around one and half year's income for a family in a rural area, much more affordable that a small traditionally powered car. The attraction of a LSEV lies not only with its low price, but also with its low running costs. The cost of the electricity needed to travel $100 \mathrm{~km}$ is around $6 ¥(\$ 0.9)$; for a small gasoline powered car the cost for the same distance would be $49 ¥$ (\$7.5), or eight times higher.

The battery can be charged overnight from an ordinary 220 volt outlet. Households in rural areas have private parking spaces where vehicles can be recharged, which is more convenient than gasoline-powered vehicles as the petrol station network in such areas is not well developed. The cost of the battery is reduced through a system of recycling. The cost of a battery (about $4000 ¥ / \$ 600$ ) is included in the initial purchase price of the LSEV. The battery can be used for one or two years, depending on the distances travelled, after which consumers pay around $2000 ¥(\$ 300)$ for a replacement. The used battery is then processed, recycled and reused.

While the LSEV has a clear value proposition to (low-income) consumers in rural areas, it also offers advantages to a segment of the more affluent urban market. Since most urban commuting distances are less than $20 \mathrm{~km}$ and the top speed of a LSEV corresponds to the standard downtown speed limit of $50 \mathrm{~km} / \mathrm{h}$, it could also answer the basic daily transportation needs of many urban consumers who currently use electric bicycles, scooters and motorcycles. It has also been suggested that the simplicity of LSEVs, where the driver need only learn to accelerate, break and to drive forwards and backwards, might prove attractive to other categories of 
drivers, such as urban housewives and senior citizens, who may feel more comfortable driving such vehicles at a low speeds. However, while this urban market exists in theory, LSEVs are not recognized as road vehicles and changes to China's legislative framework are needed before this potential can be realized.

\section{Building a market for LSEVs}

The first plans to build LSEVs in the Shifeng Group were made in 2004 but production did not start until 2007. By the end of 2007, 5000 units had been sold, mostly to existing rural customers who lived in the immediate vicinity of the plant that produced them. This modest local success acted as a spur to the Shifeng Group to look for a way to obtain a license to produce and sell LSEVs to the national market.

The first problem they faced was that LSEVs are not seen as road vehicles. Two options were open to Shifeng. The first was to apply for an electric vehicle (EV) license from The Ministry of Industry and Telecommunication, which would put the LSEV on the same footing as the electric car. However, as LSEVs do not fit within the current definition of an EV, this ruled out the possibility of getting approval without first getting a change to the legislation that defines EVs. The other option was to get a license to use LSEVs as sightseeing vehicles from AQSIQ (The General Administration of Quality Supervision, Inspection and Quarantine of the People's Republic of China), an authority that is under the direct jurisdiction of the State Council. While this option presented fewer practical problems, it meant that the vehicles could only be used in designated areas and still could not be used on public roads. 
Comparing these two options, the entry barrier to getting a license to produce electric sightseeing vehicles was clearly lower and, in June 2009, the Shifeng Group was given its license and its potential market grew from exclusively off-road rural use to rural and limited urban use. In order to expand the market further, LSEVs would need to be allowed to use the public roads.

Although modifications to national laws that deal with car registration, transportation security and management are not permitted, provincial governments are able to create temporary local policies. The Shifeng Group is located in the Gaotang county of Liaocheng city. The group contributes around 76 per cent of the total taxes paid to Gaotang County and has worked closely with local government to mobilize support for the legalization of LSEV use on public roads. In July 2008, the authorities there made a special arrangement to allow Shifeng's LSEVs to use public roads. By the end of 2009, sales of LSEVs reached 10,000, 2000 of which were sold in overseas markets. Although Shifeng and other LSEV producers have had a measure of success at the local level, if the market is to expand further, change is needed at the national level.

Shifeng has actively sought change in legislation at the national level. Several key decision makers have been invited to visit Shifeng Group, including members of the Development Research Centre of the State Council, the Ministry of Technology and the Ministry of Industry and Telecommunication. The status of the Shifeng Group as a state-owned enterprise has also allowed Mr. Liu Yifa, president of the group, in his capacity as a Deputy to the National People's Congress (the legislative house in China), to argue for measures to support LSEVs by central government. The redrafting and delay in the publication of the policy document 'Energy Efficiency and New-Energy Automotive Industry Planning (2011-2020)' is partly attributed to the mobilization of an interest group for LSEVs. 
Outside China, LSEVs have already begun to find markets with foreign institutional buyers such as governments, police departments, hospitals, post offices and airports buying Chinese LSEVs as a low cost 'green solution'. Similarly, a small number of private consumers in the US and Europe have bought LSEVs as a low cost alternative to second or third car. However, as we shall see below, there is currently a great deal of uncertainty about future of LSEVs in China with a several outcomes being possible.

\section{THE IMPLICATIONS FOR MAINSTREAM WESTERN CARMAKERS}

In an earlier paper (Wang and Kimble, 2011) we outlined three possible scenarios for the future development of the LSEV market in China.

The first scenario is based on the previous experience of e-bicycles and lowspeed farm vehicles in China. In this scenario, central government does not encourage the development of LSEVs but waits for the market to overcome existing legal and institutional barriers. If the development of LSEVs follows this trajectory then, due to the low cost of entry, the industry will remain fragmented for perhaps another 10 years after which restructuring and concentration, driven mainly by competition, will reduce the number of companies. Depending on developments elsewhere, this may, or may not be to the disadvantage of the Chinese LSEV manufacturers.

The second scenario offers a more pessimistic forecast. Here the central government deliberately limits the growth of LSEVs, preferring instead to favour the development of designs that try to recreate the key features of western passenger vehicles. If transport regulations are not changed to allow the use of LSEVs on the road and no standards for LSEVs are established, this will hinder the 
development of LSEV and place Chinese manufacturers in direct competition with European and American car giants. Although Chinese automobile manufacturers have shown themselves to be capable of remarkable innovations, this scenario will undoubtedly prove a challenge.

The final scenario sees the LSEV industry flourishing thanks to appropriate interventions by central government combined with the active engagement of individual companies and local governments. In this scenario, the expansion into international markets acts as a boost to LSEV production in China and the commercialization of low-speed electric vehicles elsewhere. While the outlook for the LSEV industry in China might be optimistic, it will almost certainly have a negative impact elsewhere.

Clearly, the direct competitive impact that the development of the LSEV in China would have elsewhere will depend on which of these scenarios is followed, but regardless of this, the development of successful a 'LSEV Business Model', in China or elsewhere, could have profound implications for the existing automobile giants.

Looking first at the LSEV in China, because of its low price, low running costs and the ease of charging from a domestic 220 volt electric outlet, the LSEV offers a clear value proposition to low-income consumers, particularly those living in rural areas. It offers the basic utility of a car, the relatively short range is not a problem as most commuting distances are small and it can be charged overnight. In addition, the use of LSEVs does not require the construction of the specialist charging stations needed for standard EVs, which has acted as an inhibitor to their spread in both rural and urban areas. In addition, as we have noted, most Chinese consumers do not have the fixed notions of 'a vehicle' (i.e. a passenger car) or 'an electric vehicle' that the mainstream western consumers have, which may make this type of simple technology more easily accepted. 
Outside China, the potential of LSEVs appears more limited. The utility of a low-speed, short-distance, EV may seem obvious, but could it have the significant, or even revolutionary, implications alluded to in the earlier sections of this chapter? Will the LSEV ever be more than a technically inferior product that serves the specific needs of a particular group of consumers in a niche market? The key question here is can the LSEV offer a similar value proposition to people outside of China.

Without entering into a analysis of the history of the automobile in Europe and America such as that offered by Calkins (2009), it is safe to say that, for most western consumers, a passenger car is thought of as a long distance cruising vehicle that has the capacity of reaching relatively high speeds. The size of fuel tank, the power of the engine and a long history of use has led us to expect our cars to carry us for long distances at speeds in excess of $100 \mathrm{~km} / \mathrm{h}$. However, the reality is that most of people live in urban areas, are subjected to the speed limits of $50 \mathrm{~km} / \mathrm{h}$ or less and travel under $50 \mathrm{~km} /$ day. Viewed as a simple matter of economics, this approach is a clear waste of resources for most urban users.

For LSEVs to offer an alternative there would have to be a change in the way we think about personal transport, a LSEV for urban usage and public transport or some other form of fuel-efficient vehicle for long distances; however this would raise a series of complex questions. These include questions of politics (Calkins, 2009), the social utility of car ownership (Steg et al., 2001), the legacy of urban planning based around car use (Newman et al., 1995) and a growing environmental concern among consumers about dwindling natural resources and pollution (Goldemberg, 1998).

While the LSEV is unlikely to provide the answer to all of these issues, it is clear that it offers many of the same advantages to western consumers as it does to those in China: simplicity, low cost and the removal of one of the main hurdles to 
the spread of the EVs, charging stations. Thus, if the right business model can be found to commercialize this potential then the LSEV could prove to be disruptive in the sense that Mitchell and Coles use the term, placing competitors 'out of position and unable to respond effectively' (Mitchell and Coles, 2003: 15).

Currently the LSEV is something of a curiosity: a product that in global terms is clearly inferior but that serves the needs of a specific geographical and social niche. However, if the right business model can be found, then the LSEV also has the potential to be 'disruptive' in Bower and Christensen's (1995) sense of the term, currently only suitable for the needs of a niche market but with the capability of improving to the extent that it could meet the (changed) needs of a wider market. 


\section{REFERENCES}

Amit, R. and Zott, C. (2001) 'Value creation in e-business', Strategic Management Journal, 22(6-7): 493-520.

Anand, N. and William, R. B. (2008) 'Innovation-oriented operations strategy typology and stage-based model', International Journal of Operations and Production Management, 28(8): 748-771.

Anderson, J. and Markides, C. (2007) 'Strategic innovation at the base of the pyramid', Sloan Management Review, 49(1): 83-88.

Bower, J. L. and Christensen, C. M. (1995) 'Disruptive technologies: catching the wave', Harvard Business Review, 73(1): 43-53.

Calkins, M. (2009) 'King car and the ethics of automobile proponents' strategies in China', Journal of Business Ethics, 85(supplement 1): 157-172.

Chesbrough, H. W. (2007) 'Business model innovation: it's not just about technology anymore', Strategy and Leadership, 35(6): 12-17.

Chesbrough, H. W. (2010) 'Business model innovation: opportunities and barriers', Long Range Planning, 43(2-3): 354-363.

Chesbrough, H. W. and Rosenbloom, R. S. (2002) 'The role of the business model in capturing value from innovation: evidence from Xerox Corporation's technology spin-off companies', Industrial and Corporate Change, 11(3): 529555.

Christensen, C. M. (1997) The innovator's dilemma: when new technologies cause great firms to fail. Boston, MA: Harvard Business Press.

Christensen, C. M., Craig, T. and Hart, S. (2001) 'The great disruption', Foreign Affairs, 80(2): 80-95.

CSY. (2010) China statistical yearbook. 
Eisenhardt, K. M. (1989) 'Building theories from case study research', Academy of Management Review, 14(4): 532-550.

Goldemberg, J. (1998) 'Leapfrog energy technologies'. Energy Policy, 26(10): 729-741.

Hart, S. and Christensen, C. M. (2002) 'The great leap: driving innovation from the base of the pyramid.' MIT Sloan Management Review, 44(1): 51-55.

Jacobson, M. Z. (2009) 'Review of solutions to global warming, air pollution, and energy security', Energy and Environmental Science, 2(2): 148-173.

Khan, A. R. and Riskin, C. (1998) 'Income and inequality in China: composition, distribution and growth of household income, 1988 to 1995 ', The China Quarterly, (154): 221-253.

Leavy, B. (2007) 'Managing the risks that go with high-impact strategies in uncertain markets', Strategy and Leadership, 35(4): 43-46.

London, T. and Hart, S. L. (2004) 'Reinventing strategies for emerging markets: beyond the transnational model', Journal of International Business Studies, 35(5): $350-370$.

Magretta, J. (2002) 'Why business models matter', Harvard Business Review, 80(5): $86-92$.

Markides, C. (2006) 'Disruptive innovation: in need of better theory', Journal of Product Innovation Management, 23(1): 19-25.

Mitchell, D. W. and Coles, C. B. (2003) 'The ultimate competitive advantage of continuing business model innovation' Journal of Business Strategy, 24(5): 1521.

Mitchell, D. W. and Coles, C. B. (2004) 'Business model innovation breakthrough moves', The Journal of Business Strategy, 25(1):16-26. 
Morris, M., Schindehutte, M. and Allen, J. (2005) 'The entrepreneur's business model: toward a unified perspective', Journal of Business Research, 58(6): 726735.

Newman, P., Kenworthy, J. and Vintila, P. (1995) 'Can we overcome automobile dependence? Physical planning in an age of urban cynicism', Cities, 12(1): 5365.

Osterwalder, A., Pigneur, Y. and Tucci, C. L. (2005) 'Clarifying business models: origins, present, and future of the concept', Communications of the Association for Information Systems, 15: 1-25.

Ranis, G. (1988) ‘Analytics of development: dualism', in Chenery, H. and Srinivasan, T. N. (eds) The handbook of development economics (Vol. 1). Amsterdam: North-Holland.

Romm, J. (2006) 'The car and fuel of the future', Energy Policy, 34(17): 26092614.

Sánchez, P. and Ricart, J. (2010) 'Business model innovation and sources of value creation in low-income markets', European Management Review, 7(3): 138-154.

Steg, L., Vlek, C. and Slotegraaf, G. (2001) 'Instrumental-reasoned and symbolicaffective motives for using a motor car', Transportation Research Part F: Traffic Psychology and Behaviour, 4(3): 151-169.

Teece, D. J. (2010) ‘Business models, business strategy and innovation', Long Range Planning, 43(2-3): 172-194.

Wang, H. (2002). The reconstruction of Chinese automobile industry, what is the trajectory towards globalization?. Grenoble: University of Pierre Mendès.

Wang, H. and Kimble, C. (2010a) 'Betting on Chinese electric cars? - analysing BYD's capacity for innovation', International Journal of Automotive Technology and Management, 10(1): 77-92. 
Wang, H. and Kimble, C. (2010b) 'Low-cost strategy through product architecture: lessons from China', Journal of Business Strategy, 31(3): 12 - 20.

Wang, H. and Kimble, C. (2011, June) 'Business model innovation in the Chinese electric vehicle industry', presented at the 19th International Gerpisa Colloquium, Is the second automobile revolution on the way?, Paris.

Yang, D. T. and Hao, Z. (1999) 'Rural-urban disparity and sectoral labour allocation in China', Journal of Development Studies, 35(3): 105-133.

Yin, R. K. (2003) Case study research: design and methods (3rd ed. Vol. 5). Thousand Oaks, CA: Sage.

Zhao, J. (2006) 'Whither the car? China's automobile industry and cleaner vehicle technologies', Development and Change, 37(1): 121-144. 